\title{
منصفة العديل بن الفرخ العجلي - مقاربة موضوعاتية
}

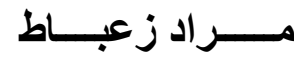

$$
\begin{aligned}
& \text { كلية الآداب و اللغات } \\
& \text { جامعة الإخوة منتوري } \\
& \text { قسنطينة الجز ائر - }
\end{aligned}
$$

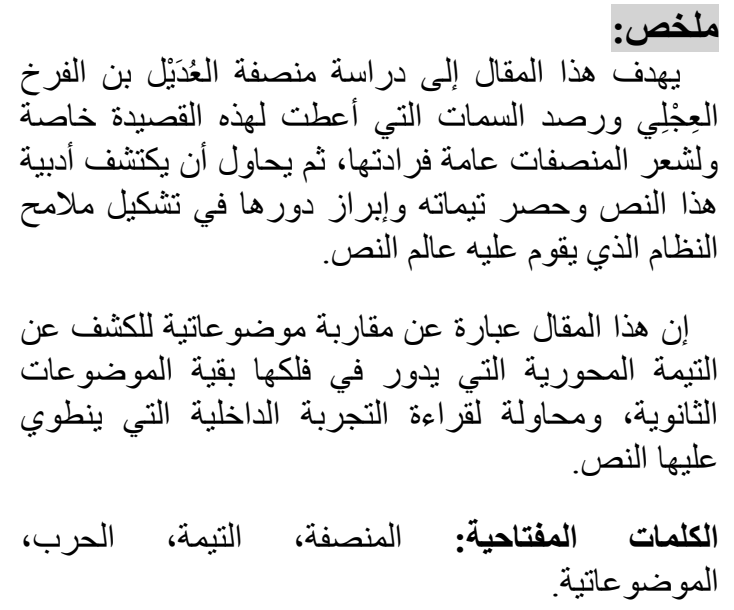

\section{مقدّمة: Résume :}

يـهدف المقال إلى دراسة منصفة

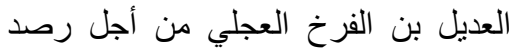

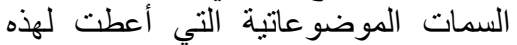
القصيدة فرادتها، مع الكثنف عن أدبية هذه النها

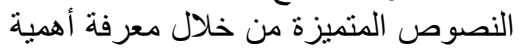
تيمات النص في تشكيل ملامح الثعرية في الثي

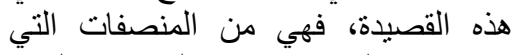
توخى فيها الثعر اء موقف الحياد في الحكم الحئ بين قبيلتهم وبين أعدائها، أو بينهم وبين الوفين

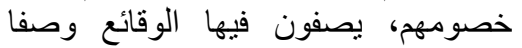

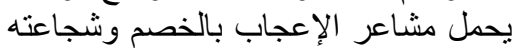

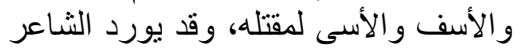

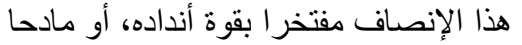

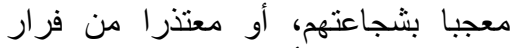
مبررا هروبه من أعدائه مشيدا بقوتهم.
La présente étude, basée sur l'approche du thème, et qui aborde le poème dit d'équité du poète Alodail Ibn Alfarkh Alajli, a pour objectif, d'une part, de mettre en lumière les caractéristiques de ce poème qui font de lui et de son genre une singularité. D'autre part, elle essaye de découvrir la littérarité de ce texte exceptionnel et de mettre en relief ses thèmes ainsi que son rôle dans la constitution des aspects du système sur lequel repose la structure du texte. Nous avons également mis en avant les images et les éléments récurrents dans le texte afin de retrouver le thème principal autour duquel tournent le reste des thèmes secondaires.

Enfin, nous avons essayé d'analyser l'expérience vécue interne que renferme le texte. 
وقد آثرت المنهج الموضو عاتي لأهميته الكبيرة في دراسة النص الثُعري و البحث عن التيمات الأساسية

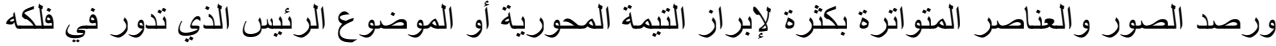

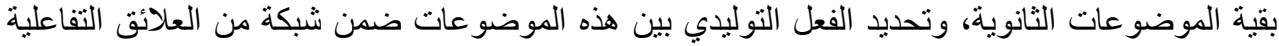
والإدماجية التي تشكل جمالية النص الثعري.

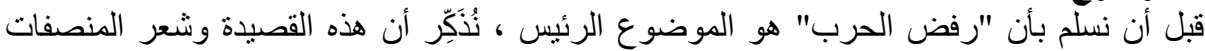

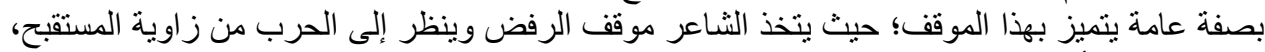

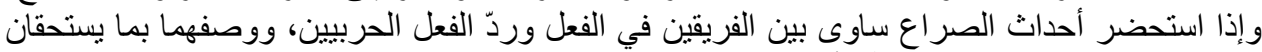

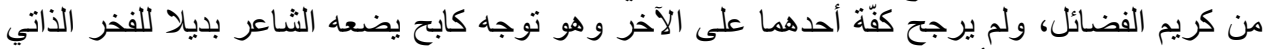

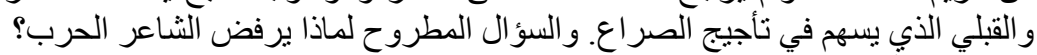

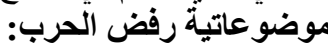

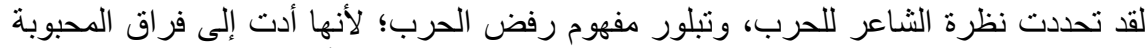

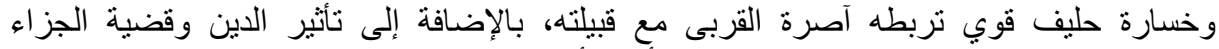

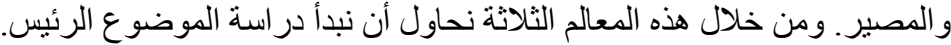

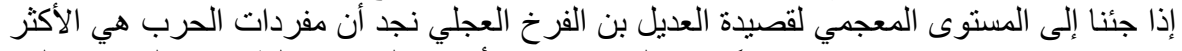

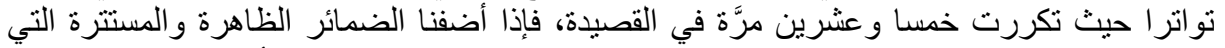

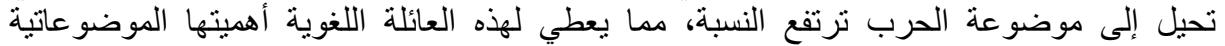

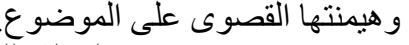

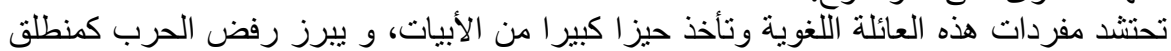

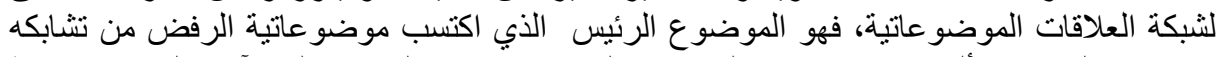

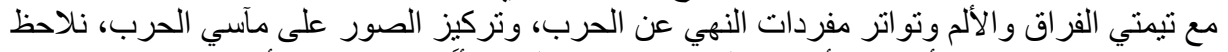

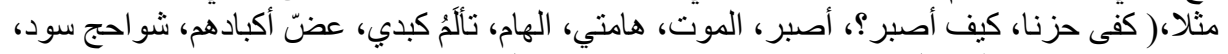

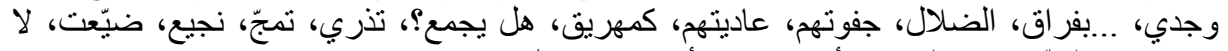

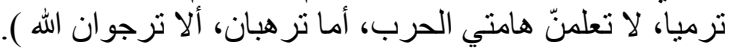

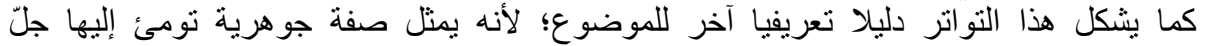

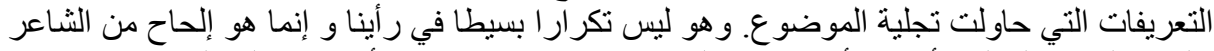

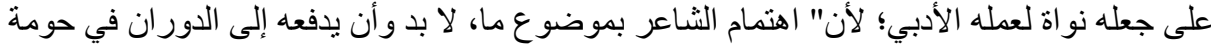

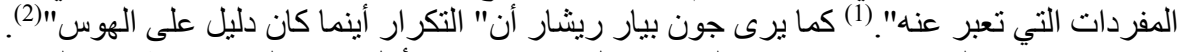

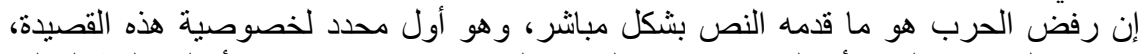

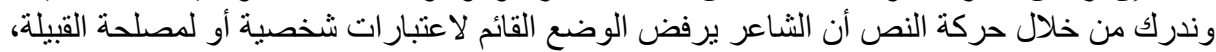

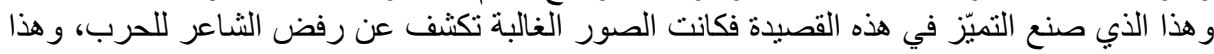

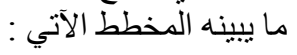




\section{مخطط يمثل تيمة الحرب وتفرعاتها}

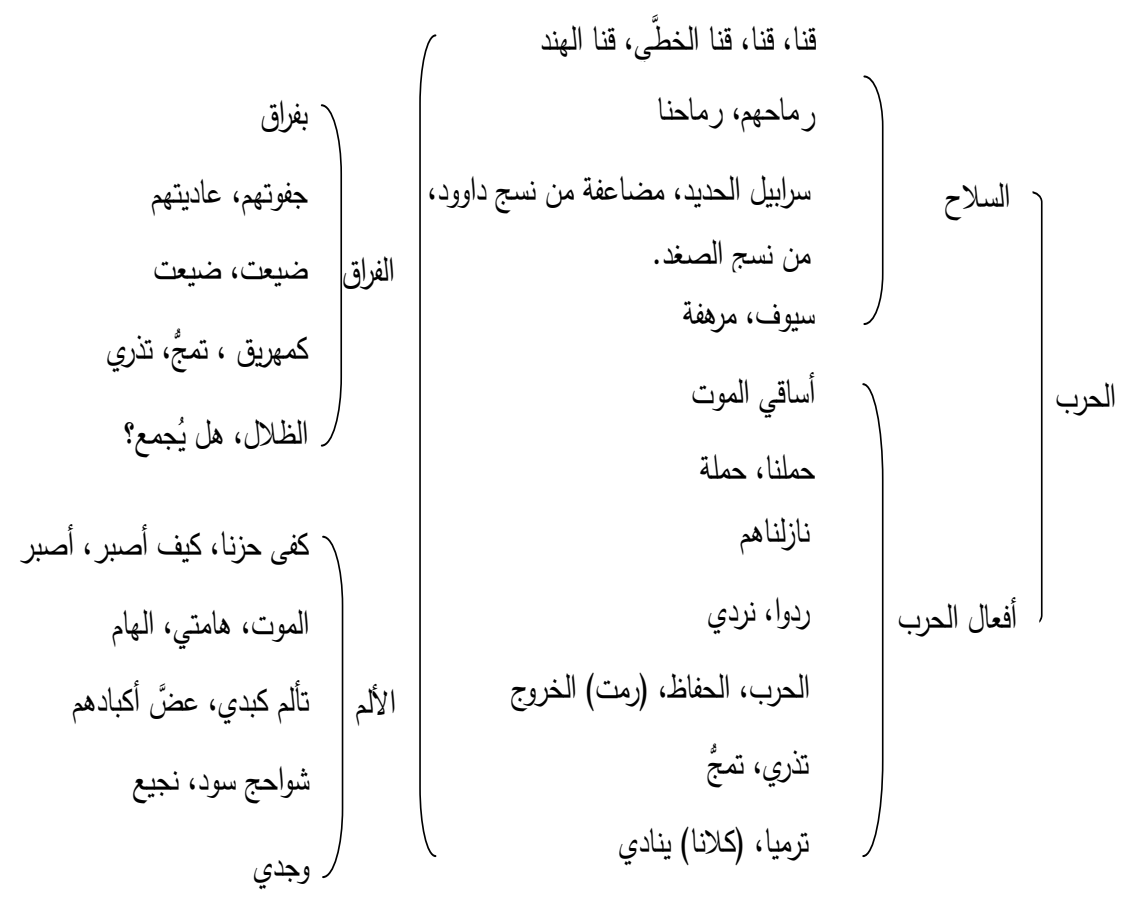

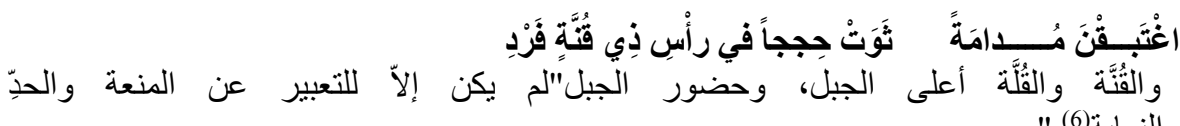

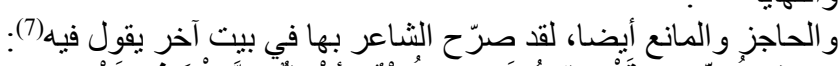

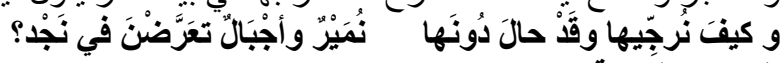

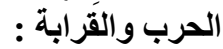

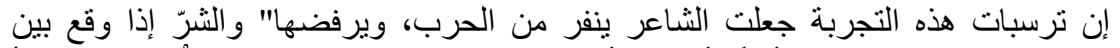

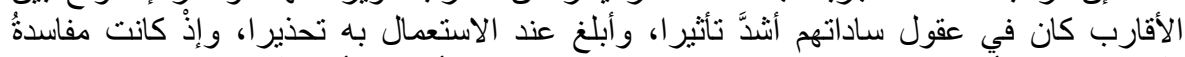

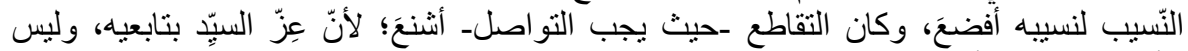

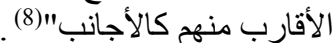

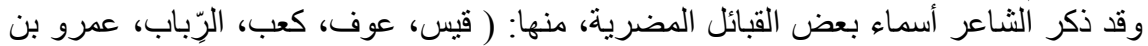

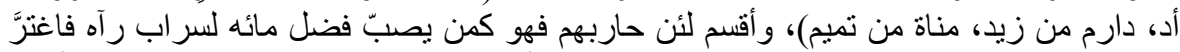

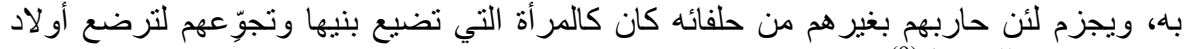

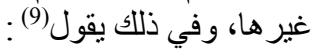




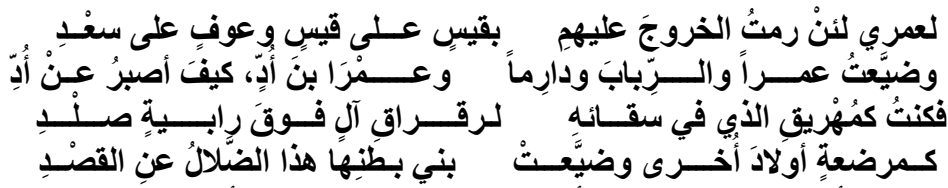

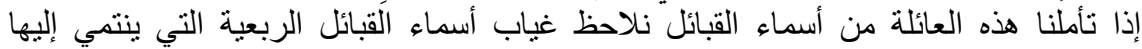

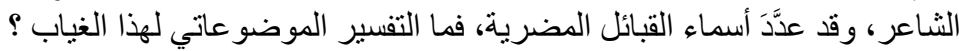

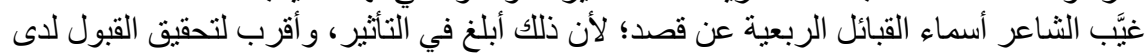

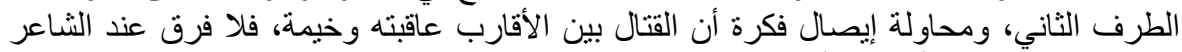
بين ربعي ومضرب لأنهم من أب و احدان.

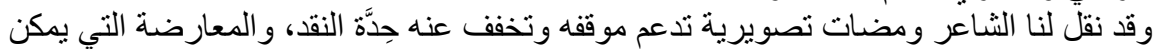
أن تثور ضد مسعاه في تحقيق الصلح من جهة، ومن جهة أخرى محاولته التأثير في الآخر، لكي لكي التئي يقبل الصلح ويوقف الحرب الدئ الدائرة بينهما: فأشار إلى أن كلا الفريقين أبطال كرماء شرفاء جِّدّو التسليح (قروم نزارية تتسامى)، (عليهم مضاعفة من نسج داود د و السغد).

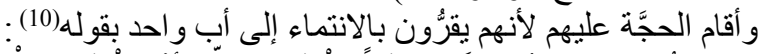

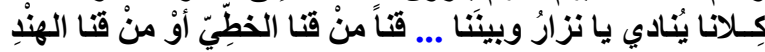

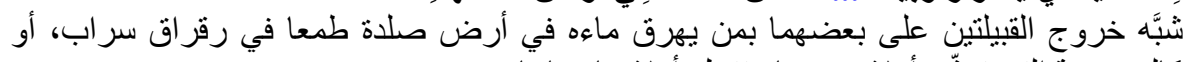

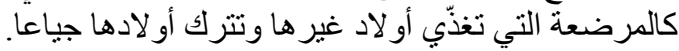

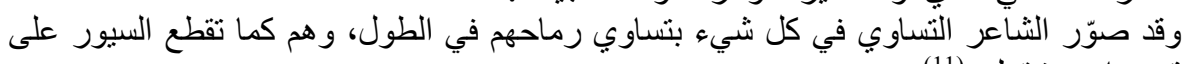

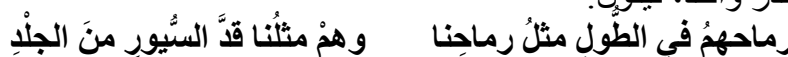

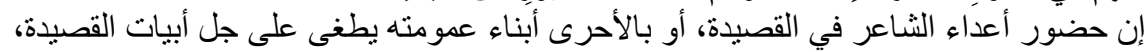

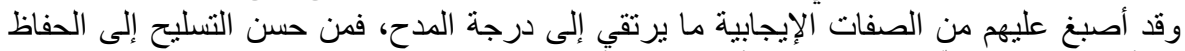

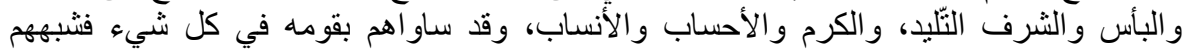

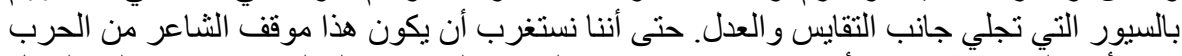

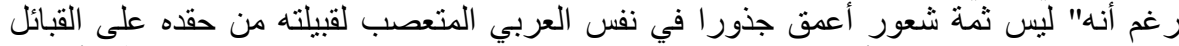

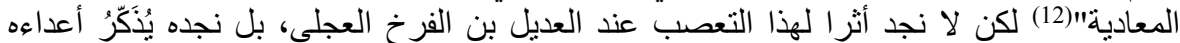

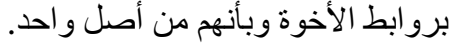


مخطط يمثل تيمة القرابة وتفرعاتها

$$
\begin{aligned}
& \text { إخواني } \\
& \text { ذراعي، عضدي } \\
& \text { الإقرار بالخطأ } \\
& \text { أبوهم أبي، جدّهم جدِّي، } \\
& \text { خالهم خالي خالي. } \\
& \text { نزار } \\
& \text { ابني نزار } \\
& \text { ابني نزار. } \\
& \text { أنتما الأكثر عددا } \\
& \text { أنتما ركنا الأرض } \\
& \text { قروم من نزار } \\
& \text { نتساوى في الحرب والنسب }
\end{aligned}
$$

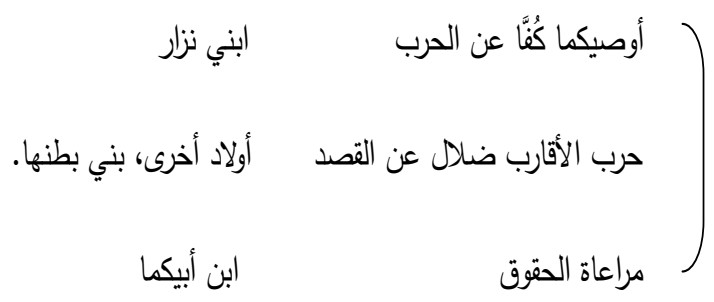

في هذا المخطط نلاحظ أن الثاعر يلح على التذكير بوحدة الأصل، فالجد واحد والأب واحد،

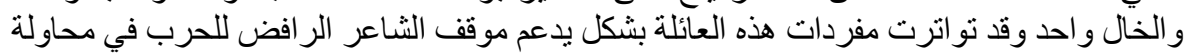

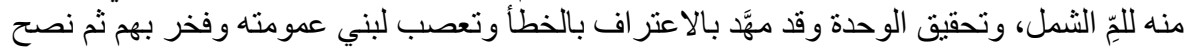

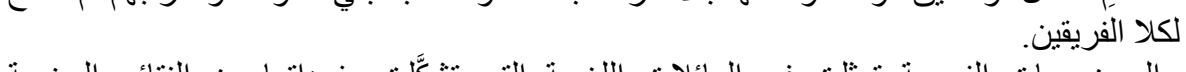
الموضوعات الفرعية نمثلت في العائلات اللغوية التي تشكَّت مفرداتها من النتائج الوخيمة

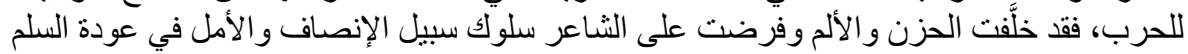




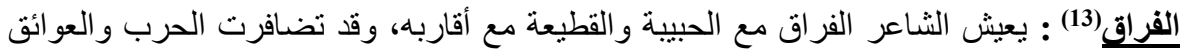

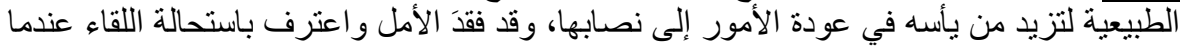

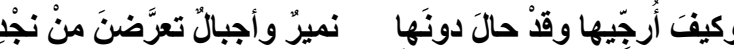

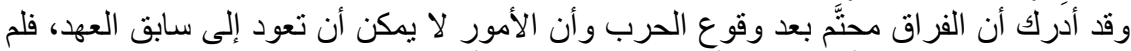

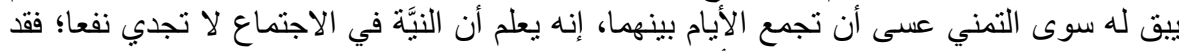

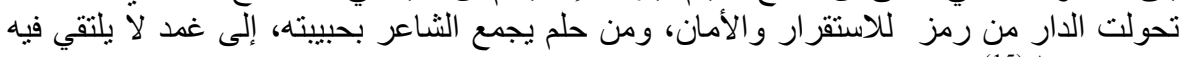

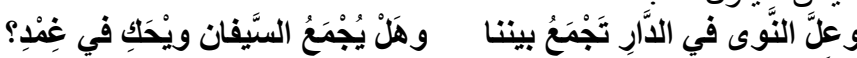

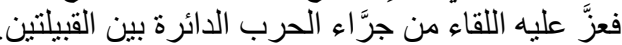
وقد صرّح بعض عاء الثعر اء بذللك، وكثفوا عن التأثير المأساوي لالتقاء موضوعي الحب و الحرب،

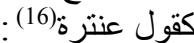

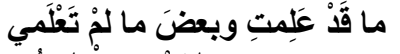

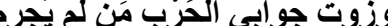

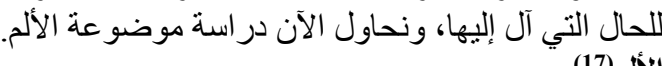

بسيطر الألم على وجدان الثاعر حتى يتمنى أن تصمت الغربان الناعقة لأنها تهيّج أحزانه

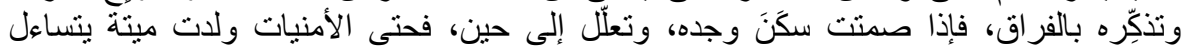

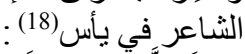

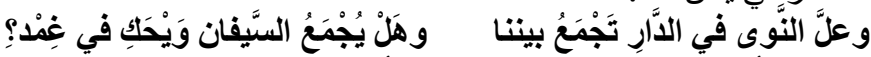

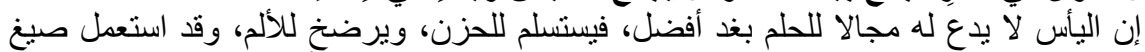

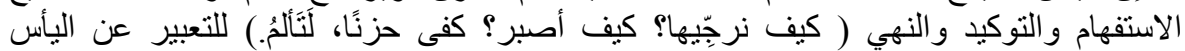

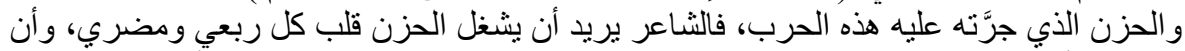

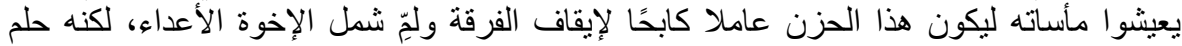

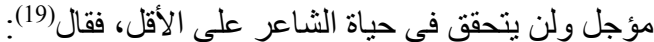

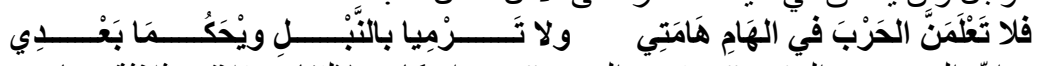

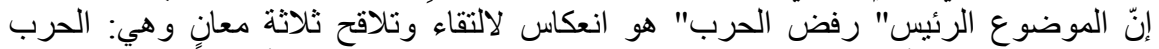

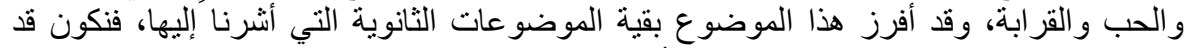

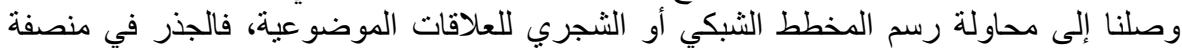

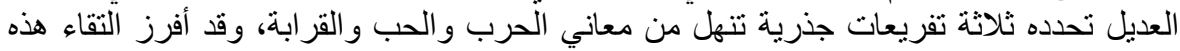

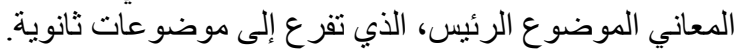


منصفة العديل بن الفرخ العجلي - مقاربة موضوعاتية

شبكة العلاقات الموضوعاتية في منصفة العديل بن الفرخ العجلى:

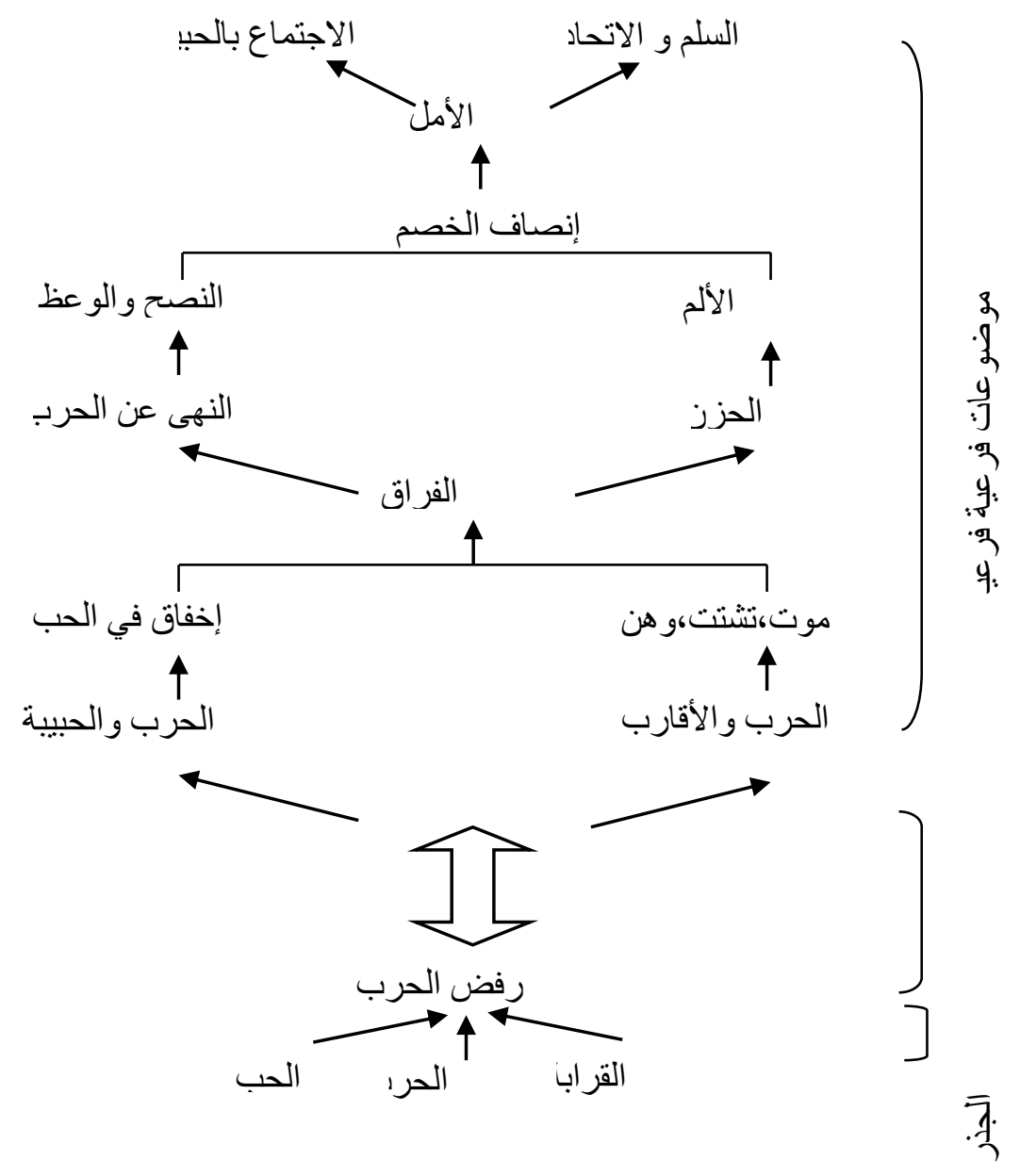

الجذور السيكولوجية لرفض الحرب عند العديل بن الفرخ العجلي:

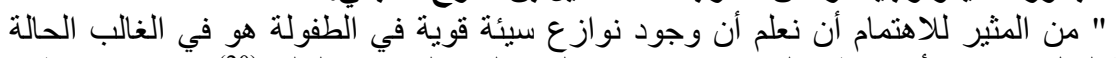

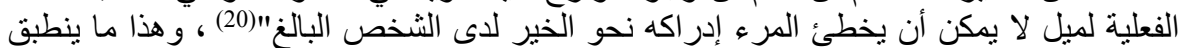

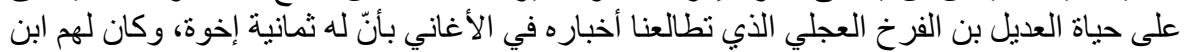

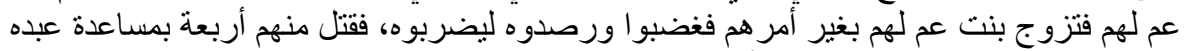
دابغ ونجا العديل بجرح غائر في الرأس.

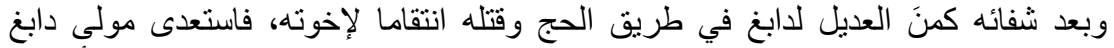

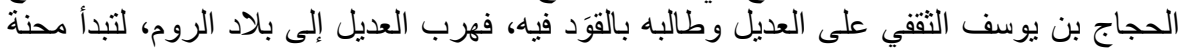

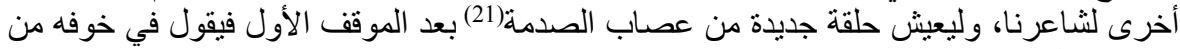

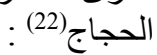




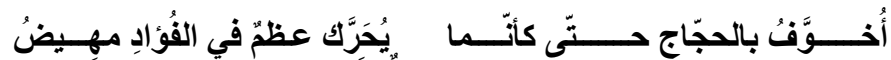

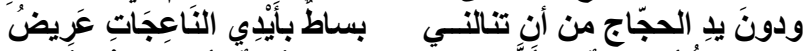

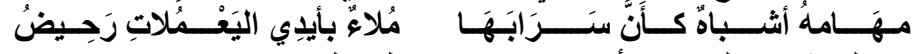

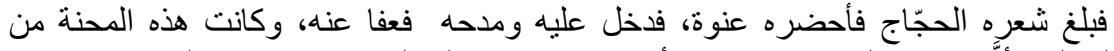

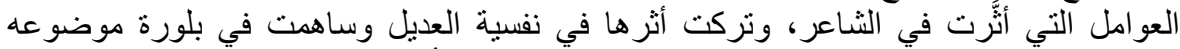

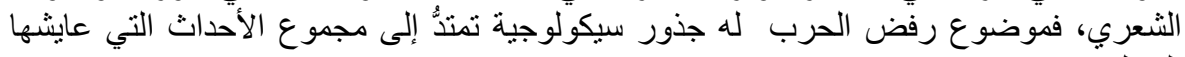

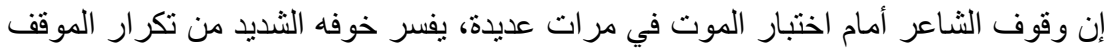

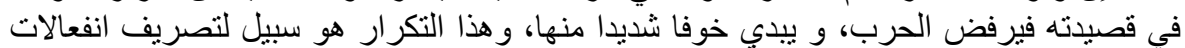

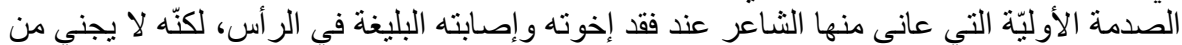

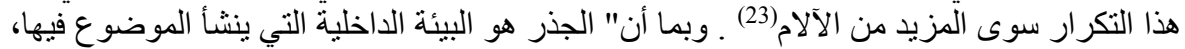

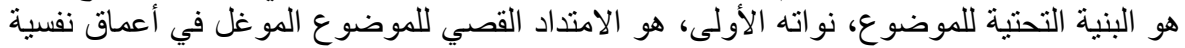
بهيمة، هو القانون السيكولوجي الذي يحكم الظاهرة الموضو عاتية، وهو النص النص في ارتباطه بالجهاز النفسي لصاحبه" (24).

ونحاول هنا أن نلج إلى العالم النفسي للعُديل بن الفرخ العجلي لاستجلاء الدلالات الخفية للقصيدة

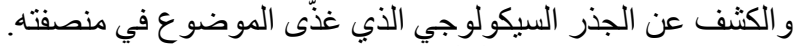
تجليات عقدة النبب(25) في القصيدة:

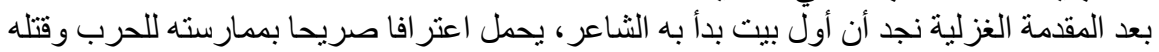

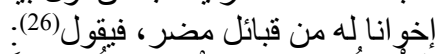

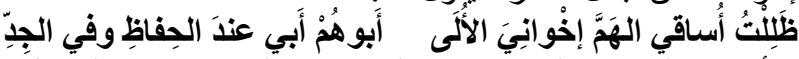

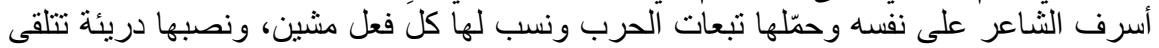

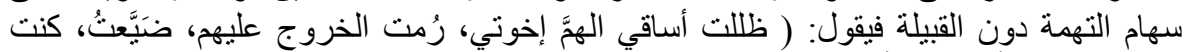

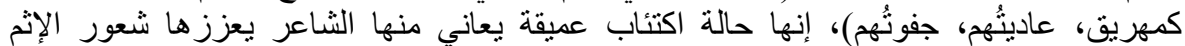

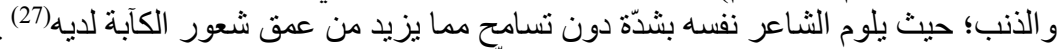

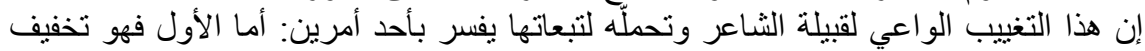

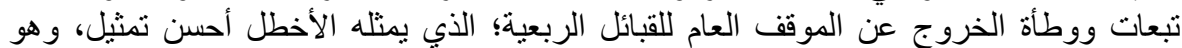
موقف التعصب للقبيلة فلا يُلام إذا أنصف أعداء هاء العها.

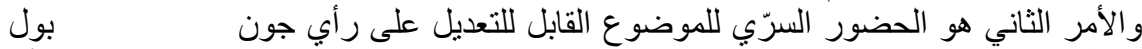

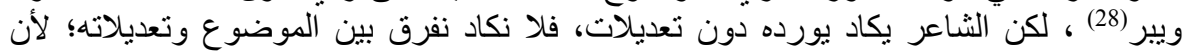

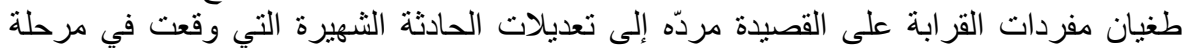

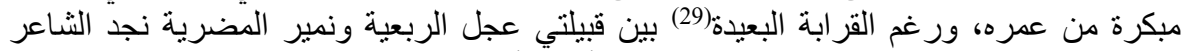

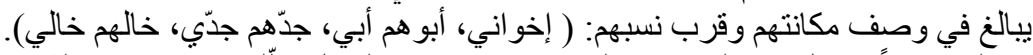

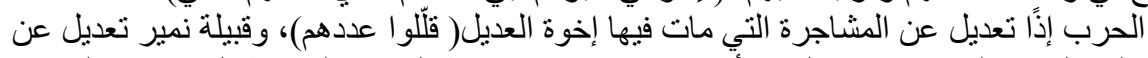

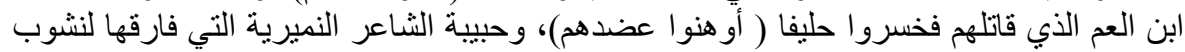

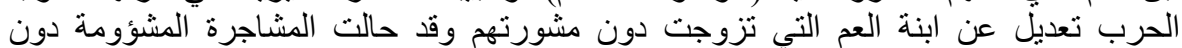

رهاب الحرب أو الهروب من الأكرى المؤلمة:

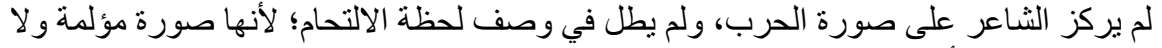

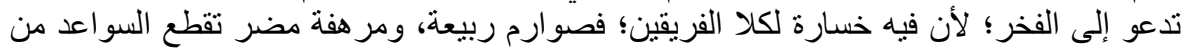
أعلاها، ولا نترك بقية من قوة القبيلتني؛ فيهرب الثناعر سريعا من الموقف، ويفصنح عن حزنه

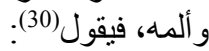




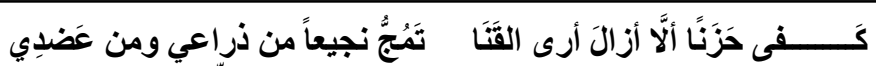

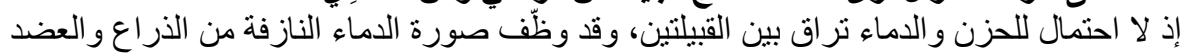

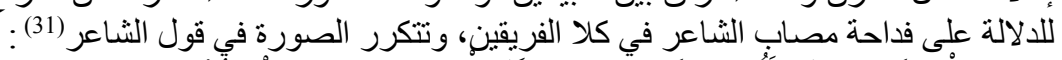

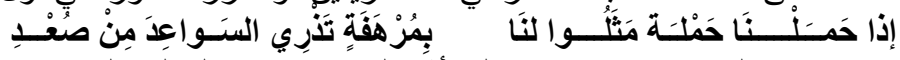

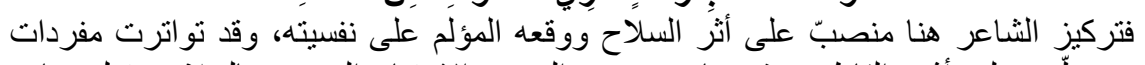

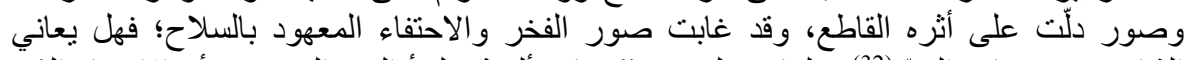

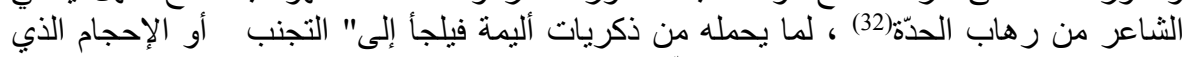

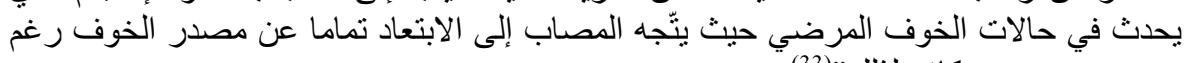

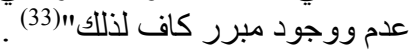

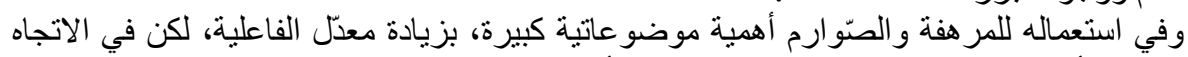

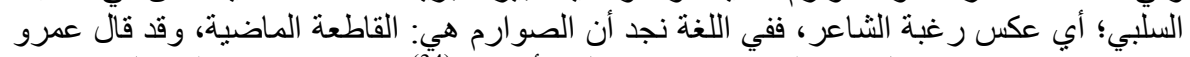

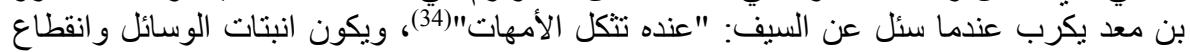

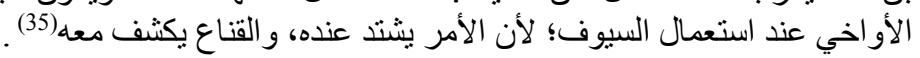

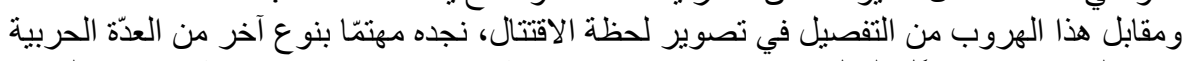

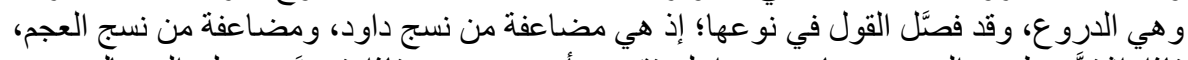

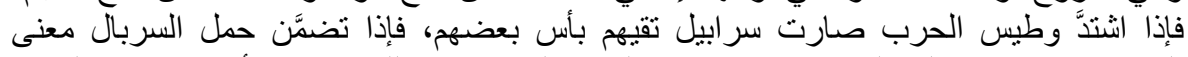

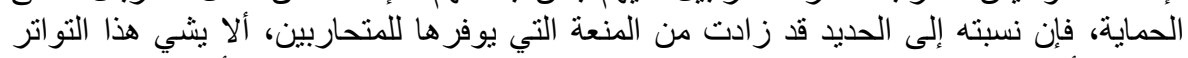

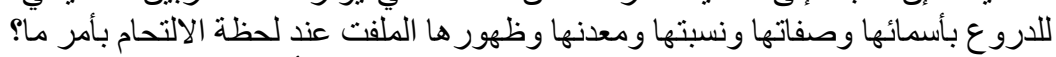

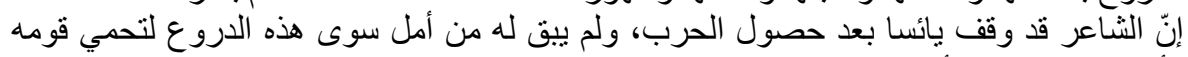

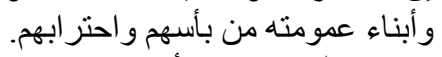

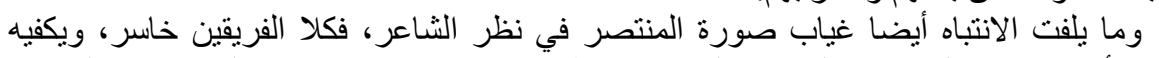

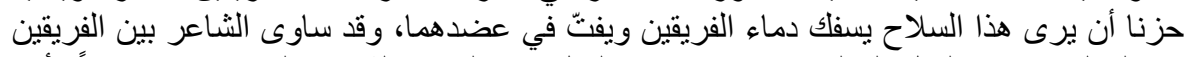

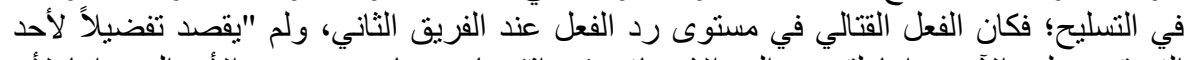

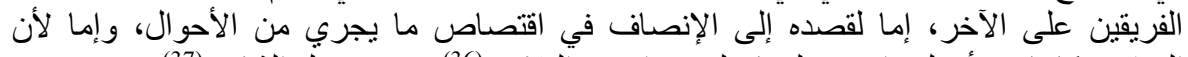

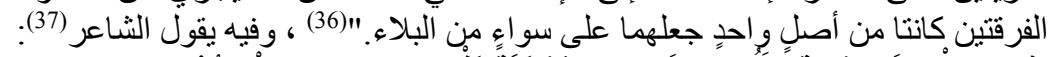

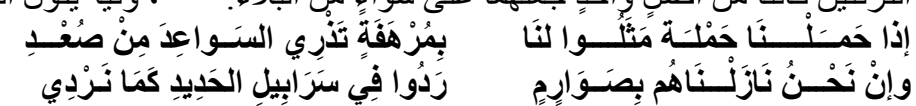

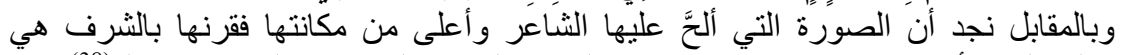

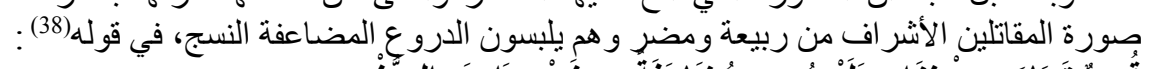

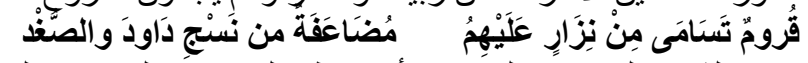

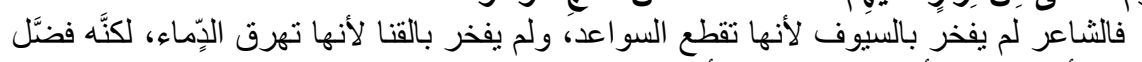
الدروع لأنها تحميه و أبناء عمومته من بأسهر و احتر الفراعه.

\section{الجزاء و المصير وتأثير هما في موقف الثاعر (39) :}

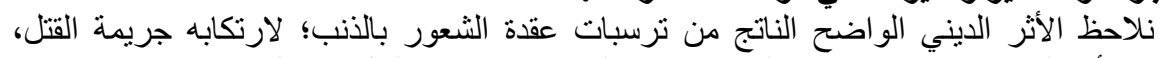

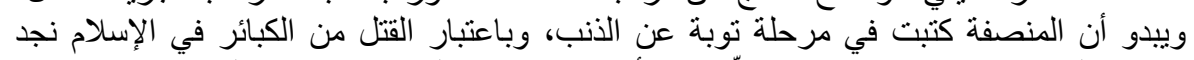

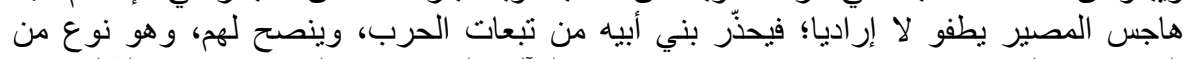

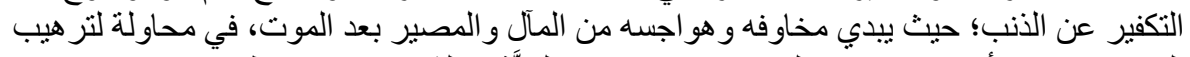

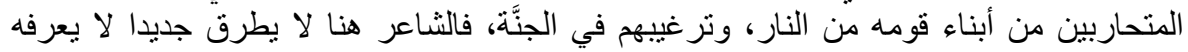

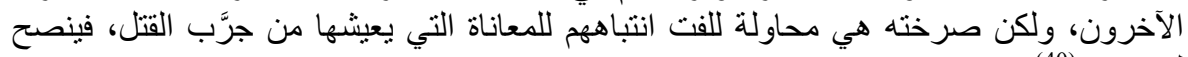

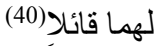

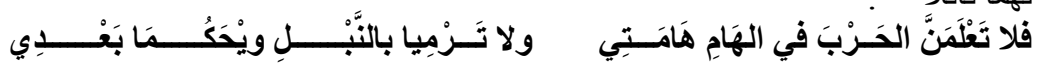




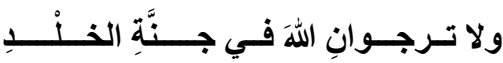

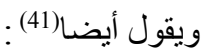

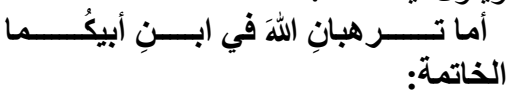

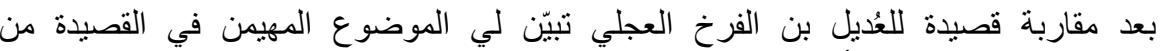

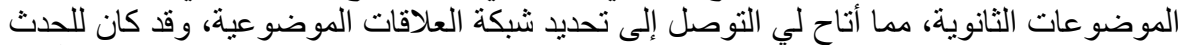

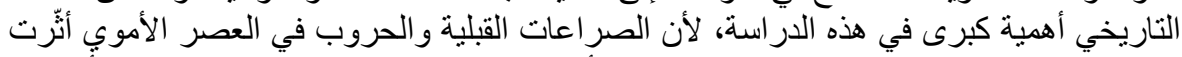

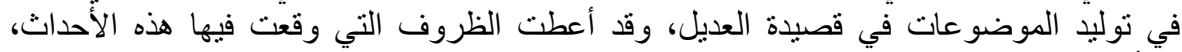
والأطراف المتسبية فيها، وموقف الثاعر منها تميزا لهذه القصيدة عن شعر الحماسة السائد في الطي

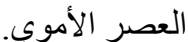

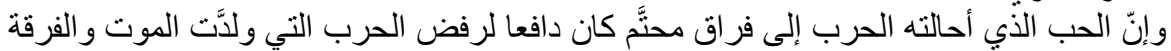

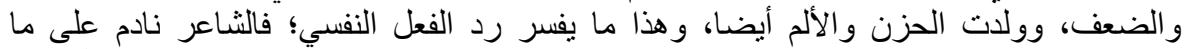

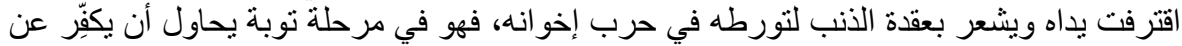
ذنبه بإنصاف أعدائه ودعو تهم للوحدة و والسلّ.

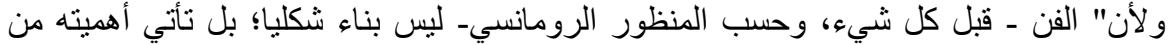
قدرته على توليد تجربة ما، وإنتاج معنى يؤثر في الحياة. ويتفق جميع النقاد ذوي النائ الاتجاه الموضو عاتي حول هذه النقطة" (42)

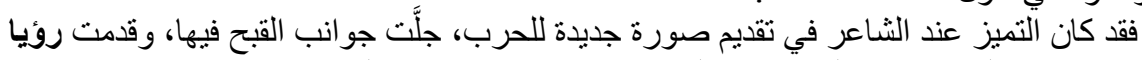

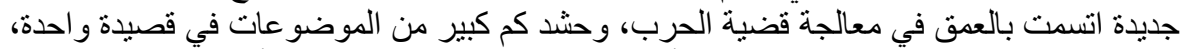

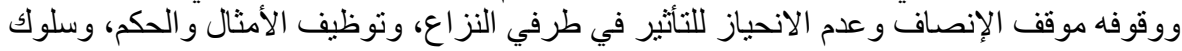

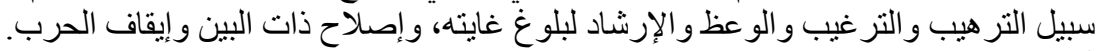

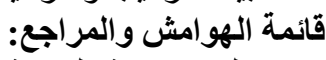
1- الموضوعية البنيوية دراسة في شعر السياب، عبد الكريم حسن، المؤسسة الجامعية للاراسات

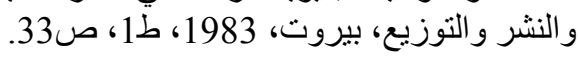

2- L'univers imaginaire de Mallarmé, Richard Jean-Pierre, Edition du seuil, Paris, 1961, p25.

3- شرح حماسة أبي تمام، أبو الحجاج يوسف بن سليمان الثنتمرّي، تح، علي المفضل حمودان، دار

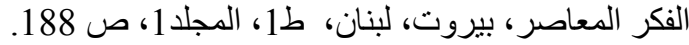

4- صوت البغل، بيتعار للالالة على صوت الغران الغراب المسن، وكان العرب ينطيرون منه ويسمّونه حاتما

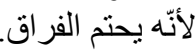

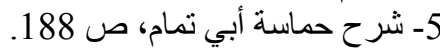

6ـ فلسفة المكان في الشعر العربي، حبيب مونسي، ديوان المطبوعات الجامعية، الجزائر، 2011، ص

7- 1 شر ح حماسة أبي تمام، ص 185

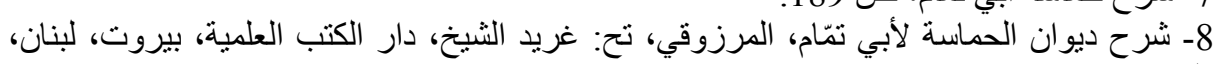

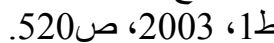

9- المصدر نفسه، ص 10 191، 1920 192، 193.

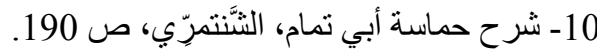

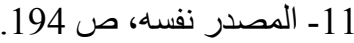

12- العصبية القبلية وأثرها في الثُعر الأموي، إحسان النص، دار الفكر ، دمشق، ط1، 1973، ص90. 13- أنظر تفرعات هذه التيمة في المخطط السابق.

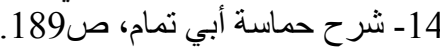


15 - 15 المصدر نفسه، ص 189.

16-ديوان عنترة، تح: محمد سعيد مولوي، المعند المكتب الإسلامي، 1964، ص220. 17 - 16 انظر تفر عات هذه ندان التيمة في المخطط السابق.

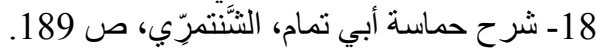

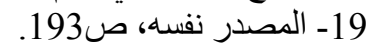
20- الحب والحرب و الحضارة والموت، سيغوند فرويد، تر: عبد الدنعم حفني دار الرشاد، القاهرة،

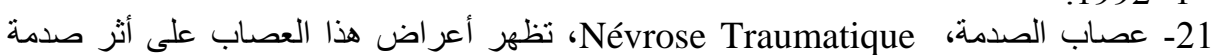

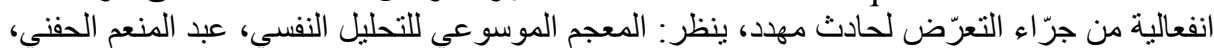

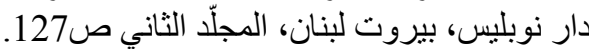

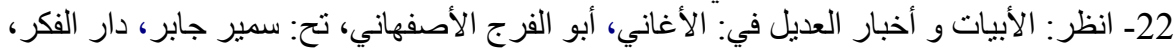

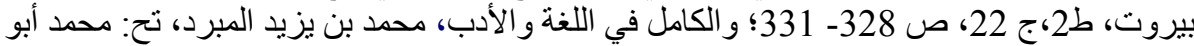

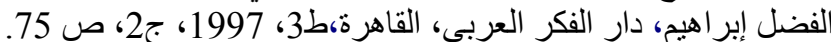

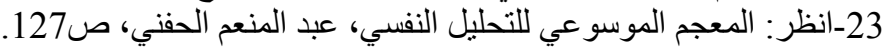

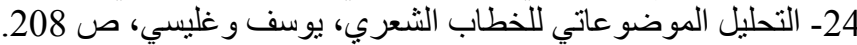

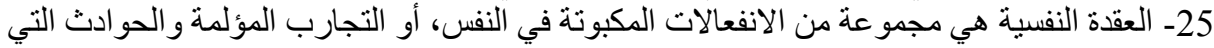

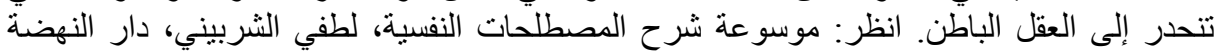

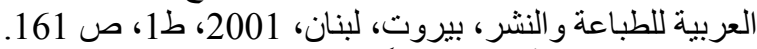

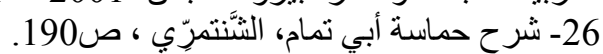

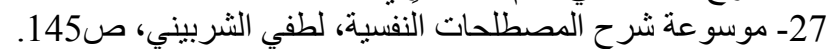

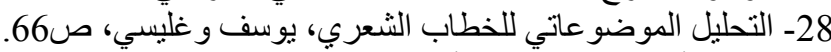
29 يقول الأخطل في البكريين أبناء عمومته:

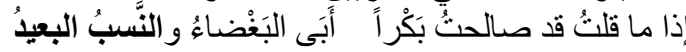
البيت في الأغاني، أبو الفرج الأصفهاني، تح: سمير جابر، دالئُ دار الفكر ، بيروت، ط2، ج8، ص 322.

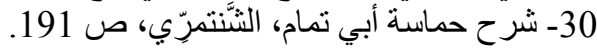

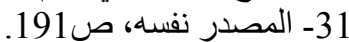

32- رُهاب الحدّة: ( الخوف من الآلات الحادّة )، خوف مرضي الحئ ممن الآلات الحادّة مثل السكاكين

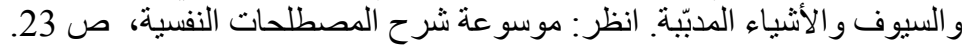

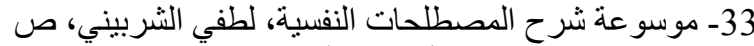

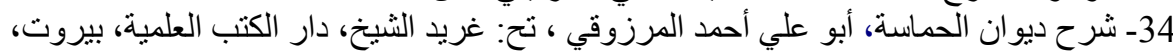

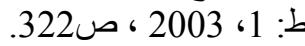
35- 35 المصدر نفسه: ص ص ص 129.

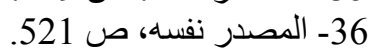

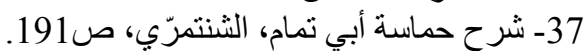

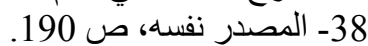

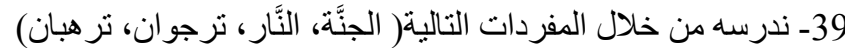

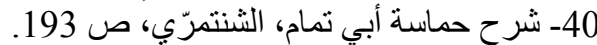

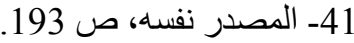

42- مدخل إلى مناهج النقد الأدبي، تر : رضو ان ظاظا، علم المعرفة، الكويت، ص98. 